\title{
Towards a More Sustainable City: The Role of the Daylight Factor in Evaluating the Energy Requirements of Buildings
}

\author{
Benedetta Mattoni, Fabio Bisegna, Alessandro Mangione \\ SAPIENZA University of Rome, Department of Astronautical, Electrical and Energy Engineering, Rome, Italy \\ Email: benedetta.mattoni@uniroma1.it, fabio.bisegna@uniroma1.it, alessandro.mangione@uniroma1.it \\ Gianfranco Rizzo, Gianluca Scaccianoce \\ Dipartimento di Energia, ingegneria dell'Informazione, e modelli Matematici, Università degli Studi di Palermo, Italy \\ Email: gianfranco.rizzo@unipa.it, scaccia@dream.unipa.it \\ Michele Zinzi \\ ENEA, Rome, Italy \\ Email: michele.zinzi@enea.it
}

\begin{abstract}
The Daylight factor is the reference parameter used in Energy Standard EN15193:2008 to assess daylight contribution in the energy performance of buildings. But its efficacy in putting in relation buildings energy performance, daylight availability and visual tasks is now a subject of discussion in literature. In fact, the daylight factor is a static indicator independent from building geometry and environmental parameters. From the energy point of view, it has still to be assessed if it can ensure when the switch of artificial light is needed, representing therefore the most disadvantageous outdoor illuminance conditions. The goal of this study is demonstrating if the daylight factor calculated in standard conditions (Overcast sky) is conservative respect to that calculated using the diffuse component of the horizontal illuminance under CIE (Commission Internationale de l'Éclairage) Clear sky. If so, Daylight factor (D) might be applied, possibly with suitable corrections, to estimate the energy requirements for lighting, keeping the results on the safe side.
\end{abstract}

Index Terms - daylight factor, energy, daylight availability, overcast sky

\section{INTRODUCTION}

Daylight is an essential resource for building users and it has a psycho-physiological role, impacting health and wellbeing [1,2]. It is also an important resource in terms of energy and economic efficiency, since the availability of daylight allows to lower the use of artificial lighting, and consequently of energy [3]. In addition, daylight allows to reduce $\mathrm{CO}_{2}$ emissions and global warming to which artificial lighting systems are main contributors [4, $5]$.

The latest issues are crucial: electricity consumption increases the most in the future scenario of the world energy policies, rising by $80 \%$ from 2012 to 2040 [6].
Among the electricity energy uses, artificial lighting nowadays contributes for the $20-60 \%$ of the annual energy consumption in non-residential buildings (about one-third of the electricity budget) [7,8]. In terms of economic advantages, improvements in lighting design allow high reduction of energy bills in non-residential buildings, which ranges from $30 \%$ to $70 \%$ of the total energy budget [9]. Field measurements on daylighting in a fully air-conditioned, daylit corridor have shown that energy savings in electric lighting are approximately $65 \%$ [10]. A crucial issue is, however, the implementation of reliable methods to estimate the energy requirements for lighting, without going through time and money consuming operational methods and taking into account the contribute of daylight. The only available scheme, recognised at international level, is the standard EN15193:2008 (EC-1:2011) [11], which establishes the calculation method for the estimation of lighting energy consumption in non-residential buildings and provides an indicator of lighting energy requirements for building certification (LENI). The Daylight factor is the reference parameter used in this Standard to assess daylight contribution in buildings. A critical aspect of the EN15193:2008 (EC-1:2011) [11] is the overestimation of the lighting energy use, especially in southern European countries, as reported in [12-20]. In [12] the number of daylight/non-daylight hours through a climatic data set of outdoor diffuse illuminance is calculated. These climatic data are used to determine whenever the level of mean illuminance on the working area is lower than the minimum values required by EN 12464-1 [21] and consequently the artificial lighting system needs to be switched on. Both in $[12,16]$ the Daylight Factor parameter is applied for putting in relation the outdoor and indoor lighting conditions: the strengths of this parameter are the quickness and ease of use but on the 
other side its simplicity could lead to less accurate and precise results.

The compromise between easiness and accuracy is therefore the main target to be achieved for building energy performance calculation and the analysis of the present work goes in this direction.

According to this, two main issues strongly emerged: the use of climate-based approaches, leaning on local climate data, and the need of identifying a simple but reliable daylight indicator which can put in relation buildings energy performance, daylight availability and visual tasks.

The main Standards, including the EN15193:2008 (EC-1:2011)[11], and most of the sustainability protocols have one main common element: the indicator/parameter used to assess the daylight requirement is the Daylight factor.

According to this, at the moment, the daylight factor and the indoor illuminance are the reference parameters usually applied to derive the outdoor luminous environment requirements able to ensure the fulfilment of the visual tasks. The daylight factor is therefore a simplified design indicator and its efficacy in lighting evaluation is a subject of discussion in literature.

In fact it was argued that the daylight factor is a static indicator, which does not take into account the variability of the real sky conditions and other geometrical and environmental parameters [22-25Furthermore it is stated that there is not correspondence between Daylight factor and indoor illuminance: being $\mathrm{D}$ simply a ratio, high values of $\mathrm{D}$ do not necessary coincide with high levels of illuminance and vice versa [24].

From the energy point of view, what has to be assessed is the reliability of this indicator for energy purposes: in particular if, coupled with reliable climate data, the Daylight factor is able to represent the building characteristics, to put in relation the outdoor and indoor lighting conditions and, as a consequence, to ensure when the switch to artificial light is needed. What is basically important to evaluate is if it can serve as an indicator of threshold values representing the most disadvantageous outdoor illuminance conditions, considering the standard sky condition (Overcast)

In fact, as highlighted by [22] it has not been yet defined in literature what the concept of "most conservative" condition really means, if it is due to the values of diffuse horizontal illuminance of the sky or due to the sky luminance distribution

\section{AIMS AND METHODS}

Starting from these assumptions, the goal of this study is to verify if the Standard Overcast sky represents the most disadvantageous condition for $\mathrm{D}$ calculation which is defined as the ratio of the indoor horizontal illuminance $E_{m}$ on the outdoor diffuse horizontal illuminance $E_{d h}$. Consequently, it will be possible to understand if, coupled with climate data, it can be used as an efficient parameter for lighting energy performance calculations of buildings.
The aim is demonstrating if the daylight factor with Overcast sky is conservative respect to that calculated using the diffuse component of the horizontal illuminance under CIE Clear sky.

In this case, D might be usefully applied, possibly with suitable corrections depending on geographic locations, to estimate the energy requirements for lighting, keeping the results on the safe side (i.e. predicted energy uses greater than the effective ones).

\section{CASE StUdy AND CALCUlation TOOL}

To achieve this target a numerical test was carried out on a representative office building, where D calculations were performed with several building orientations, date and time. A set of hourly simulations was thus carried out for the 2 solstices and 1 equinox (for symmetry). The operation hours run from 8:00 until 16:00. Combining the possible variables assumed in the parametric study a total amount of 192 cases was analyzed.

In this research the software DIVA for Rhino was used for simulations, it has been combined with 3D modelling software Rhinoceros as interface and includes Radiance as calculation engine [26]. A crucial issue for this study was the generation of sky types. The embedded code gensky [27] provides RADIANCE scene descriptions for the CIE standard sky distribution at the given month, day and time and location to fulfill the objective of the paper the Clear without Sun Radiance Sky was used. The criterium of selection is based on the assumption that the daylight factor has to be calculated taking into account the sky diffuse component only. The position of the sun influences the sky luminance distribution in the clear and intermediate skies, but the contribution of the direct radiation is excluded. Preliminary analyses showed that the selected Radiance skies best fits with the CIE Clear Sky number 12 .

The daylight factor calculation has been carried out with on a reference office of an isolated building near Rome, Italy. The building is facing north and south and has no external obstructions; it has a rectangular plan of $48 \times 12 \mathrm{~m}$ and consists of two floors of $2.7 \mathrm{~m}$ height as shown in Fig. 1. The offices facing north are separated by a corridor from offices facing south. Each office has a single double-glazed window.

\section{RESUlTS}

A parametric evaluation has been carried out, highlighting the variation of average Daylight factor $\left(D_{\text {avg }}\right)$ as sky type, hour and building orientation change. Being symmetrical the results of east and west orientations, only the data obtained with East orientation are shown.

For the same reason, only autumn data are shown as exemplificative of solstice condition. In general, it emerged that, the differences of $\mathrm{E}_{\mathrm{m}}$ and consequently of $\mathrm{D}_{\text {avg }}$ using the two types of skies are considerable. $\mathrm{D}_{\text {avg }}$ calculated with Overcast sky is frequently conservative compared to Clear sky especially when the window is directly exposed to the circumsolar region (region of the 
sky closest to the Sun). In fact, despite the direct contribute of Sun is excluded, the presence of the circumsolar region influences the luminance distribution of Clear sky. It determines that $\mathrm{D}_{\text {avg }}$ calculated using Clear sky is affected by orientation, hours and date.

Furthermore, as shown in the following tables and graphs, it has to be noted that the due to different way of reprocessing the extraterrestrial solar radiation (transformed into sky radiation for Overcast sky and apportioned between sky radiation and the Sun for Clear Sky) by Radiance, the values of $E_{d h}$ with Clear sky without sun are much lower in Summer and Autumn compared to Overcast sky. In fact, being the Sun excluded from calculation in the Clear sky without Sun, also the extraterrestrial solar radiation apportioned to the Sun is not considered. In winter the two outdoor illuminances are quite aligned since the sky luminance values which are used by the software for calculating outdoor illuminances are similar even if the distribution is different.

The combination of these two factors (lower values of $\mathrm{E}_{\mathrm{dh}}$ than Overcast sky and position of the circumsolar region respect to the window) make the $\mathrm{D}_{\text {avg }}$ calculated under Overcast sky be frequently lower and consequently conservative compared to $\mathrm{D}_{\text {avg }}$ calculated under Clear Sky: being indoor illuminance higher and outdoor illuminance lower the result of this ratio is a higher value of $D_{\text {avg }}$ calculated with Clear sky.

On the contrary $\mathrm{D}_{\text {avg }}$ calculated with Overcast sky is lower or equal to $\mathrm{D}_{\text {avg }}$ calculated under Clear sky when in the last case window is not exposed to the sun (East orientation in the afternoon and North orientation in the central hours of the day) and contemporary the $\mathrm{E}_{\mathrm{dh}}$ under Overcast sky is much higher than the one under Clear sky. More specific results of the analysis are shown for different orientations.

\section{A. North}

In Table I and Fig. 1 the comparisons of illuminances and $\mathrm{D}_{\mathrm{avg}}$ values between Clear and Overcast sky in summer solstice and autumn equinox are shown. In winter solstice, not shown in figure or table, $D_{\text {avg }}$ calculated under Overcast sky is always conservative compared to the one under Clear sky.

In summer solstice, $D_{\text {avg }}$ calculated with Clear sky is equal or lower than the one obtained with Overcast sky only in the central hours of the day, when window is the least exposed to the sun so that $E_{d h}$ and indoor illuminance $\left(\mathrm{E}_{\mathrm{m}}\right)$ under clear sky are lower. The maximum negative percentage differences of $E_{d h}, E_{m}$ and $\mathrm{D}_{\text {avg }}$ between the two sky types (Clear sky has lower values than Overcast sky) are registered at 12:00 and are respectively $-47 \%,-49 \%$ and $-0.2 \%$

The same condition can be seen in Fig. 2 for autumn equinox in the central hours of the day where the maximum negative percentage differences of $E_{m}$ and $D_{a v g}$ was found at 12:00, being respectively and are respectively $-41 \%,-44 \%$ and $-0.3 \%$.
TABLE I. COMPARISON BETWEEN OVERCAST AND CLEAR SKY, 21ST OF JUNE, NORTH FACING WINDOW

\begin{tabular}{|c|c|c|c|c|c|c|c|}
\hline $\begin{array}{c}\text { June } \\
\mathbf{2 1}\end{array}$ & $\begin{array}{c}\mathbf{E}_{\text {dh }} \\
\mathbf{C l e a r} \\
{[\mathbf{l u x}]}\end{array}$ & $\begin{array}{c}\mathbf{E}_{\mathrm{dh}} \\
\text { Ove } \\
{[\mathbf{l u x}]}\end{array}$ & $\begin{array}{c}\mathbf{D}_{\text {avg }} \\
\mathbf{C l e a r} \\
{[\%]}\end{array}$ & $\begin{array}{c}\mathbf{D}_{\text {avg }} \\
\text { Ove } \\
{[\%]}\end{array}$ & $\begin{array}{c}\Delta \mathbf{D}_{\text {avg }} \\
(\mathbf{C l e}-\mathbf{O v e}) \\
{[\%]}\end{array}$ & $\begin{array}{c}\mathbf{E}_{\mathbf{m}} \\
\mathbf{C l e a r} \\
{[\mathbf{l u x}]}\end{array}$ & $\begin{array}{c}\mathbf{E}_{\mathbf{m}} \\
\text { Ove } \\
{[\mathbf{l u x}]}\end{array}$ \\
\hline $\mathbf{0 8 : 0 0}$ & 7648 & 10860 & 7.4 & 5.7 & 1.7 & 568 & 619 \\
\hline $\mathbf{0 9 : 0 0}$ & 8295 & 13625 & 6.6 & 5.7 & 1.0 & 551 & 772 \\
\hline $\mathbf{1 0 : 0 0}$ & 8586 & 15753 & 6.1 & 5.7 & 0.4 & 522 & 897 \\
\hline $\mathbf{1 1 : 0 0}$ & 8896 & 17226 & 5.8 & 5.7 & 0.0 & 519 & 1006 \\
\hline $\mathbf{1 2 : 0 0}$ & 9377 & 17833 & 5.5 & 5.7 & -0.2 & 518 & 1014 \\
\hline $\mathbf{1 3 : 0 0}$ & 9174 & 17589 & 5.8 & 5.7 & 0.1 & 536 & 1006 \\
\hline $\mathbf{1 4 : 0 0}$ & 8673 & 16522 & 5.7 & 5.7 & 0.0 & 499 & 947 \\
\hline $\mathbf{1 5 : 0 0}$ & 8429 & 14675 & 6.5 & 5.7 & 0.8 & 544 & 837 \\
\hline $\mathbf{1 6 : 0 0}$ & 8001 & 12174 & 6.9 & 5.7 & 1.2 & 556 & 696 \\
\hline
\end{tabular}

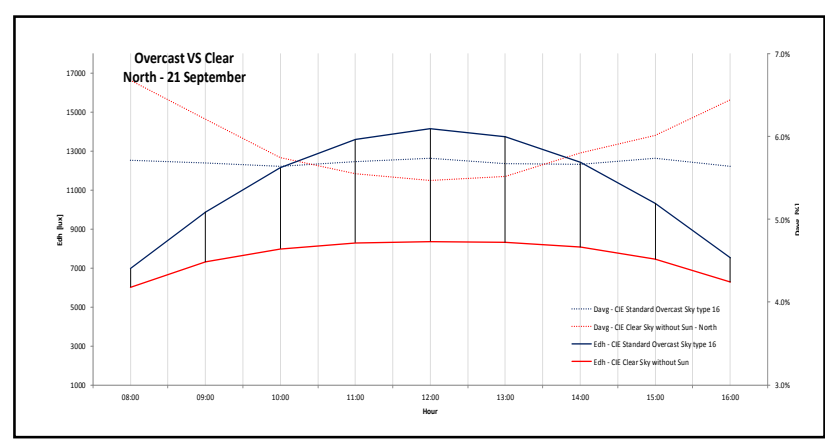

Figure 1. Comparison between Overcast and Clear skies. Trends of Davg and Edh values, 21st September, North facing window

\section{B. East}

In Table II and Fig. 2 the comparisons of illuminances and $\mathrm{D}_{\text {avg }}$ values between Clear and Overcast sky in summer solstice and autumn equinox are shown for east orientation. Also in this case in winter solstice, $\mathrm{D}_{\mathrm{avg}}$ calculated under Overcast sky is always conservative compared to the one under Clear sky. Furthermore, for all the hours in autumn equinox, $\mathrm{D}_{\mathrm{avg}}$ calculated with Overcast sky is lower and conservative.

TABLE II. COMPARISON BETWEEN OVERCAST AND CLEAR SKY, 21ST OF JUNE, EAST FACING WINDOW

\begin{tabular}{|c|c|c|c|c|c|c|c|}
\hline $\begin{array}{c}\text { June } \\
\mathbf{2 1}\end{array}$ & $\begin{array}{c}\mathbf{E}_{\text {dh }} \\
\mathbf{C l e a r} \\
{[\mathbf{l u x}]}\end{array}$ & $\begin{array}{c}\mathbf{E}_{\text {dh }} \\
\text { Ove } \\
{[\mathbf{l u x}]}\end{array}$ & $\begin{array}{c}\mathbf{D}_{\text {avg }} \\
\mathbf{C l e a r} \\
{[\%]}\end{array}$ & $\begin{array}{c}\mathbf{D}_{\text {avg }} \\
\text { Ove } \\
{[\%]}\end{array}$ & $\begin{array}{c}\Delta \mathbf{D}_{\text {avg }} \\
(\mathbf{C l e}-\text { Ove }) \\
{[\%]}\end{array}$ & $\begin{array}{c}\mathbf{E}_{\mathrm{m}} \\
\mathbf{C l e a r} \\
{[\mathbf{l u x}]}\end{array}$ & $\begin{array}{c}\mathbf{E}_{\mathbf{m}} \\
\text { Ove } \\
{[\mathbf{l u x}]}\end{array}$ \\
\hline $\mathbf{0 8 : 0 0}$ & 7648 & 10860 & 19.0 & 5.7 & 13.3 & 568 & 619 \\
\hline $\mathbf{0 9 : 0 0}$ & 8295 & 13625 & 15.3 & 5.7 & 9.6 & 551 & 772 \\
\hline $\mathbf{1 0 : 0 0}$ & 8586 & 15753 & 11.8 & 5.7 & 6.1 & 522 & 897 \\
\hline $\mathbf{1 1 : 0 0}$ & 8896 & 17226 & 8.9 & 5.7 & 3.1 & 519 & 1006 \\
\hline $\mathbf{1 2 : 0 0}$ & 9377 & 17833 & 7.2 & 5.7 & 1.5 & 518 & 1014 \\
\hline $\mathbf{1 3 : 0 0}$ & 9174 & 17589 & 6.1 & 5.7 & 0.4 & 536 & 1006 \\
\hline $\mathbf{1 4 : 0 0}$ & 8673 & 16522 & 5.5 & 5.7 & -0.2 & 499 & 947 \\
\hline $\mathbf{1 5 : 0 0}$ & 8429 & 14675 & 5.5 & 5.7 & -0.2 & 544 & 837 \\
\hline $\mathbf{1 6 : 0 0}$ & 8001 & 12174 & 5.6 & 5.7 & -0.1 & 556 & 696 \\
\hline
\end{tabular}

On the contrary, from $14: 00$ to $16: 00$ in summer solstice, when the solar altitude is very high, and the window is not exposed to the sun, Clear sky shows lower value of $D_{\text {avg. }}$. The maximum negative percentage difference of $E_{d h}, E_{m}$ and $D_{\text {avg }}$ between the two sky types (Clear sky has lower values than Overcast sky) in summer solstice are registered at 14:00 and are respectively $-47 \%,-49 \%$ and $-0.2 \%$. 


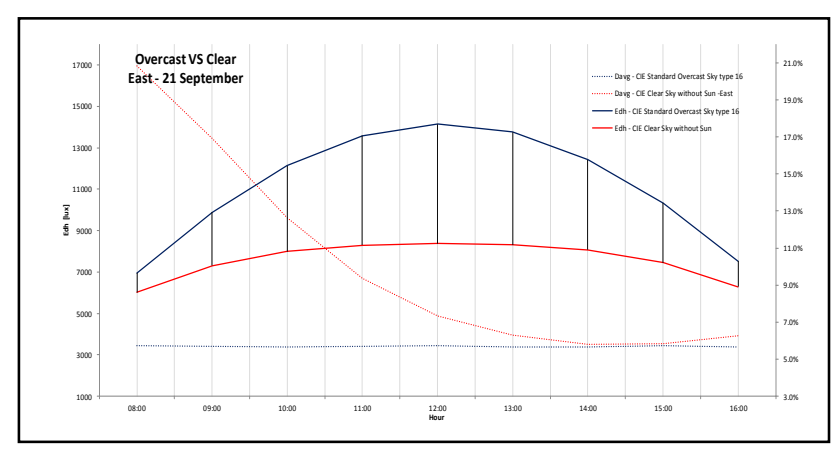

Figure 2. Comparison between Overcast and Clear skies. Trends of Davg e Edh values, 21st September, East facing window

\section{South}

For south orientation, in winter, autumn and summer days $D_{\text {avg }}$ calculated under Clear sky resulted higher than $\mathrm{D}_{\text {avg }}$ calculated under Overcast sky. This is due to the fact that window is exposed to the sun for the entire day and consequently $\mathrm{E}_{\mathrm{m}}$ is higher compared to the other orientations under Clear sky (North and East) and also higher than $\mathrm{E}_{\mathrm{m}}$ obtained with Overcast sky for South Orientation (Table III and Fig. 4).

TABLE III. COMPARISON BETWEEN OVERCAST AND CLEAR SKY, 21ST OF SEPTEMBER, SOUTH FACING WINDOW

\begin{tabular}{|c|c|c|c|c|c|c|c|}
\hline $\begin{array}{c}\text { Sept. } \\
\mathbf{2 1}\end{array}$ & $\begin{array}{c}\mathbf{E}_{\mathbf{d h}} \\
\mathbf{C l e a r} \\
{[\mathbf{l u x}]}\end{array}$ & $\begin{array}{c}\mathbf{E}_{\mathbf{d h}} \\
\text { Ove } \\
{[\mathbf{l u x}]}\end{array}$ & $\begin{array}{c}\mathbf{D}_{\text {avg }} \\
\mathbf{C l e a r} \\
{[\%]}\end{array}$ & $\begin{array}{c}\mathbf{D}_{\text {avg }} \\
\mathbf{O v e} \\
{[\%]}\end{array}$ & $\begin{array}{c}\Delta \mathbf{D}_{\text {avg }} \\
(\mathbf{C l e}-\mathbf{O v e}) \\
{[\%]}\end{array}$ & $\begin{array}{c}\mathbf{E}_{\mathbf{m}} \\
\mathbf{C l e a r} \\
{[\mathbf{l u x}]}\end{array}$ & $\begin{array}{c}\mathbf{E}_{\mathbf{m}} \text { Ove } \\
{[\mathbf{l u x}]}\end{array}$ \\
\hline $\mathbf{0 8 : 0 0}$ & 6008 & 6961 & 10.4 & 5.7 & 4.6 & 622 & 398 \\
\hline $\mathbf{0 9 : 0 0}$ & 7296 & 9893 & 11.7 & 5.7 & 6.1 & 856 & 562 \\
\hline $\mathbf{1 0 : 0 0}$ & 7992 & 12143 & 13.1 & 5.7 & 7.5 & 1049 & 685 \\
\hline $\mathbf{1 1 : 0 0}$ & 8303 & 13595 & 14.2 & 5.7 & 8.5 & 1176 & 775 \\
\hline $\mathbf{1 2 : 0 0}$ & 8385 & 14150 & 14.7 & 5.7 & 9.0 & 1234 & 812 \\
\hline $\mathbf{1 3 : 0 0}$ & 8347 & 13757 & 14.4 & 5.7 & 8.8 & 1206 & 780 \\
\hline $\mathbf{1 4 : 0 0}$ & 8078 & 12431 & 13.7 & 5.7 & 8.0 & 1105 & 704 \\
\hline $\mathbf{1 5 : 0 0}$ & 7457 & 10335 & 12.5 & 5.7 & 6.7 & 931 & 593 \\
\hline $\mathbf{1 6 : 0 0}$ & 6297 & 7534 & 10.8 & 5.7 & 5.2 & 681 & 425 \\
\hline
\end{tabular}

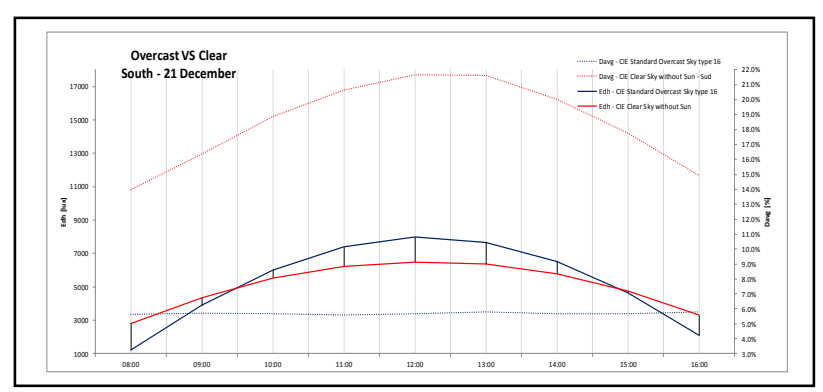

Figure 3. Comparison between Overcast and Clear skies. Trends of Davg e Edh values, 21st December, South facing window

Considering that as previously described $\mathrm{E}_{\mathrm{dh}}$ with Clear sky is lower than with Overcast sky, the result is that $D_{\text {avg }}$ under Overcast sky is always conservative at South. In Table III and Fig. 3 the comparisons of illuminances and $\mathrm{D}_{\text {avg }}$ values between Clear and Overcast sky in autumn equinox and winter solstice are shown.

\section{CONCLUSION}

Daylighting is a key factor for buildings, both in terms of comfort and energy efficiency. Nowadays European standards regulating indoor availability of daylight, from the design (visual comfort and well-being) and energy efficiency points of view (energy requirements for artificial lighting), indicate that the Daylight factor, calculated using the standard Overcast sky, is the reference parameter for daylight evaluations.

In literature, several studies have highlighted the critical issues related both to the Daylight factor and to its calculation condition for comfort and lighting design purposes. On the basis of these considerations, despite its intrinsic critical issues, the Daylight Factor is still the reference parameter for the assessment of daylight availability.

From the energy point of view, what is basically important to evaluate is if it can serve as an indicator of threshold values representing the most disadvantageous outdoor illuminance conditions and consequently if can be considered as the "switching factor" of artificial light.

This work has the purpose to evaluate whether the standard calculation condition (Overcast sky) is actually the most conservative. The $3 \mathrm{~d}$ model of an office placed near Rome was developed. The simulations have been carried out using DIVA / Radiance software; the daylight factor has been calculated by using the Overcast sky and the Clear sky without Sun. In addition to the sky model variation, several other parameters have been changed: the day of the year (equinoxes and solstices), the operating hours (8:00-16:00) and orientations.

The results show that the Daylight factor calculated with the Overcast sky is not conservative for North orientation in $20 \%$ of cases, and both for East and West in $12 \%$ of cases. Since the standard calculation conditions of the Daylight factor did not result to be the most disadvantageous compared to Clear sky without Sun, it lead to the conclusion that there is a high possibility that also compared to Intermediate sky the Overcast sky could be not the most disadvantageous condition.

A deeper exploration is therefore needed, considering for example the entire year of analysis or additional environmental variables, for understanding if the Daylight factor can still be used as parameter for energy calculation or if a more suitable parameter for daylight evaluations in buildings from the design and energy points of view must be found.

\section{ACKNOWLEDGMENT}

This work was partially supported by the PRIN (Programmi di Ricerca Scientifica di Rilevante Interesse Nazionale) of the Italian Ministry of Education, University and Research, within the research project $n$. 201594LT3F, "La ricerca per i PAES: una piattaforma per le municipalità partecipanti al Patto dei Sindaci (Research for SEAP: a platform for municipalities taking part in the Covenant of Mayors)", and partially supported by ENEA - Report Ricerca di Sistema Elettrico (Accordo 
di Programma Ministero dello Sviluppo Economico ENEA, Piano Annuale di Realizzazione 2016).

\section{REFERENCES}

[1] B. Mattoni, P. Gori, and F. Bisegna, "A step towards the optimization of the indoor luminous environment by genetic algorithms," Indoor and Built Environment, vol. 26, no. 5, pp. 590-607, 2017

[2] D. Berlov, L. Pavlova, F. Bisegna, A. Aladov, T. Baranova, J. Chiligina, and M. Mizerov, "Prospects of research of influence of lighting modes on changes of human functional state with assistance of "smart lighting" device," in Proc. the 15th International Conference on Environment and Electrical Engineering (EEEIC), Rome, Italy, June 10-13, 2015.

[3] S. Cammarano, A. Pellegrino, VRM Lo Verso, C. Aghemo, "Assessment of daylight in rooms with different architectural features, Building Research and Information," vol. 43, no. 2, pp. 222-237, 2015.

[4] D. Jenkins and M. Newborough, "An approach for estimating the carbon emissions associated with office lighting with a daylight contribution," Applied Energy, vol. 84, pp. 608-622, 2007.

[5] A. C. Doris, D. Moreno, J. Navarro, "Correlating daylight availability metric with lighting, heating and cooling energy consumptions," Building and Environment, vol. 132, pp. 170-180, 2018

[6] International Energy Agency. World Energy Outlook 2014. ISBN: 978-92-64-20805-6 Available at: www.iea.org (accessed on 30/01/2018 )

[7] M. S. Alrubaih, M. F. M Zain, M. A Alghoul, N. L. N Ibrahim, M. A. Shameri, O. Elayeb, "Research and development on aspects of daylighting fundamentals," Renewable and Sustainable Energy Reviews, vol. 21, pp. 494-505, 2013.

[8] M Dubois, A. Blomsterberg, "Energy saving potential and strategies for electric lighting in future North European, low energy office buildings: A literature review," Energy and Buildings, vol. 43, pp. 2572-2582, 2011.

[9] B. L Capehart, W. C Turner, W. J Kennedy, Guide to Energy Management, 7th Edition, Fairmont Press, 2012.

[10] D. H. W. Li, J. C. Lam, "An investigation of daylighting performance and energy saving in a daylit corridor," Energy and Buildings, vol. 35, pp. 365-373, 2003.

[11] EN 15193:2008. Energy performance of buildings. Energy requirements for lighting. Brussels, 2008 (EC-1 2011).

[12] M. Zinzi, A. Mangione, "The daylight contribution in the electric lighting energy uses: EN standard and alternative method comparison, 6th International Building Physics Conference," IPBC 2015, in Energy Procedia 2015, vol.78, pp. 2663-2668.

[13] C. Calistru, U. Pont, A. Mahdavi, "Estimation of electrical lighting energy use in buildings: A method comparison. BauSIM 2014 : Human centred building(s)," in Proc. 5th German-Austrian Conference of the International Building Performance Simulation Association (5th German-Austrian Conference of IBPSA) ; $22-24$ September 2014, RWTH Aachen University, Germany / Christoph van Treeck, Dirk Müller (eds.), 2014

[14] D. Gasparovsky, E. Erkin, S. Onaygil, and A. Smola, "A critical analysis of the methodology for calculation of the lighting energy numerical indicator (LENI)," WIT Transactions on The Built Environment, vol. 121, pp. 173-184, 2011.

[15] R. Szczepaniak, M. Wilson, "Investigating energy requirements for lighting: A critical approach to EN15193," in Proc. Conference: Adapting to Change: New Thinking on Comfort, Cumberland Lodge, Windsor, UK, 9-11 April 2010. London: Network for Comfort and Energy Use in Buildings, http://nceub.org.uk

[16] M Tian, S Yuehong, An Improvement to Calculation of Lighting Energy Requirement in the European Standard EN 15193:2007, Journal of Daylighting, vol.1, pp. 16-28, 2014.

[17] V. R. M. Lo Verso A, Pellegrino, F Pellerey, "A multivariate nonlinear regression model to predict the energy demand for lighting in rooms with different architectural features and lighting control systems," Energy and Buildings, vol. 76, pp. 151-163, 2014.

[18] S Moret, M Noro, K Papamichael, "Daylight harvesting: a multivariate regression linear model for predicting the impact on lighting, cooling and heating," in Proc. the 1st IBPSA Italy
Conference, Bolzano (Italy), January 30 - February 1, 2013, paper 328.

[19] R. W. Fonseca, E. L. Didoné, Ruttkay Pereira FO. "Using artificial neural networks to predict the impact of daylighting on building final electric energy requirements," Energy and Buildings, vol. 61 pp. 31-38, 2013.

[20] D. H. W. Li, S. L. Wong, "Daylighting and energy implications due to shading effects from nearby buildings," Applied Energy, vol. 84, pp. 1199-1209, 2007.

[21] UNI EN 12464-1:2011, "Light and Lighting - Lighting of workplaces - Part 1: Indoor work places, July 2011.

[22] J Mardaljevic, Rethinking daylighting and compliance, SDAR* Journal of Sustainable Design \& Applied Research 2013; 1(3), Article 1. Available at: http://arrow.dit.ie/sdar/vol1/iss3/1

[23] J Mardaljevic, L Heschong, E Lee, "Daylight metrics and energy savings," Lighting Research and Technology, vol. 41, pp. 261-283, 2009.

[24] J. Mardaljevic, Taking daylight modelling out of the dark ages, Available at: http://thedaylightsite.com/wpcontent/uploads/papers/Taking\%20daylight $\% 20$ modelling\%20ut $\% 20$ of\%20the \%20dark\%20ages.pdf. (accessed on 31/01/2018).

[25] Y. Bian and Y, Ma, Analysis of daylight metrics of side-lit room in Canton, south China: A comparison between daylight autonomy and daylight factor, Energy and Buildings, vol. 138, pp. 347-354, 2017

[26] Diva Software. Available at: http://diva4rhino.com/

[27] Gensky tool description. Available http://radsite.lbl.gov/radiance/man_html/gensky.1.html

Benedetta Mattoni PhD, currently a Post Doc at the Department of Astronautical, Electrical and Energy Engineering, Building Physics and Environmental Engineering Area, SAPIENZA University of Rome.

Fabio Bisegna MEng, $\mathrm{PhD}$ and Researcher at the Department of Astronautical, Electrical and Energetic Engineering, Building Physics and Environmental Engineering Area, SAPIENZA University of Rome, Italy. Member of the Doctoral Program "Energy Savings" at the SAPIENZA University of Rome, Italy. Member of the Italian National Research Council-Conservation and Valorisation of the Cultural Heritage. Current Member of Technical Committees in CIE. He was the italian key-contact for the IEA Annex 45 (2004-2009) "Energy Efficient Electric Lighting for Buildings".

Alessandro Mangione PhD student at the Department of Astronautical, Electrical and Energy Engineering, Building Physics and Environmental Engineering Area, SAPIENZA University of Rome.

Gianfranco Rizzo Full professor of Environmental Technical Physics. Head of the Department of Energy at University of Palermo. Energy Manager of the University of Palermo. Past Chairman of the Ph.D. School on Environmental Technical Physics. Research experience with the International Energy Agency and the University of California, Berkeley. Teaching experience at the University of Luanda (Angola). Responsible of international, national Italian (PRIN 2003, PRIN 2006 and PRIN 2015 on the energy efficiency in buildings), regional Sicilian and local researches projects. Responsible for the Civil Sector of the Sicilian Energy and Environmental Plan. Member of the panel of the Italian Ministry of "Cultural Goods" for the utilization of renewable energy sources in heritage buildings. Member of the panel of the Italian Ministry of Environment for the European Ecolabel brand of buildings. Author of more than 300 scientific publications. Co-author of three books on issues concerning the energy efficiency in buildings. Member of the editorial board of Int. Journal of Sustainable Development and Planning. Chair of several sessions in International conferences Reviewer of several scientific journals. Guest Editor of a Special Issue of Energy (2012). Councilor for Energy and Innovation at the Municipality of Palermo (2016/2017).

Gianluca Scaccianoce Associate Professor at the University of Palermo.

Michele Zinzi researcher at ENEA, Italy. 